\title{
Perceived warmth and skin temperature as functions of the duration and level of thermal irradiation'
}

\author{
LAWRENCE E. MARKS AND JOSEPH C. STEVENS, 2 \\ JOHN B. PIERCE FOUNDATION LABORATORY AND YALE UNIVERSITY
}

This study examined the correlations among the degree of perceived warmth, the level and duration of irradiant flux, and the thermal response of the skin. For any constant duration, perceived warmth grew as a power function of the difference between the irradiant flux of the stimulus and the flux that approximates the absolute threshold for warmth. The exponent of the power function was about 0.87 for the shortest durations (2-6 sec), but rose to 1.04 for the longest duration of exposure $(12 \mathrm{sec})$. For any constant level of flux, perceived warmth changed only slightly with duration. In contrast, superficial skin temperature, and inferred temperatures of deeper layers of the skin, rose continuously and markedly with duration. Neither the change in tissue temperature, nor the rate of change of tissue temperature, nor thermal gradient correlated consistently with level of perceived warmth. The change in the difference between the temperature $0.2 \mathrm{~mm}$ and that $1.0 \mathrm{~mm}$ below the skin surface provided a fairly good but not perfect correlate to perceived warmth. The findings suggest the possibility that sensory adaptation at the site of the receptor system mediating warmth could act in such a way as nearly to offset the effect of rising skin temperature with increased duration of stimulation.

An earlier study (J. C. Stevens \& Marks, 1967) examined the functional relation between apparent warmth and level of thermal irradiation of the skin for brief $(5-\mathrm{sec})$ periodic exposures of constant duration. The purpose of the present study is to examine how apparent warmth grows as a function not only of the level but also of the duration of exposure to the radiant source.

The earlier study demonstrated that warmth produced by thermal irradiation may be added to the long list (S. S. Stevens, 1961) of sensory continua that follow the psychophysical power law. This law states that

$$
\psi=\mathbf{k}\left(\varphi-\varphi_{0}\right)^{\beta}
$$

where $\psi$ is sensory magnitude, $\varphi$ is stimulus intensity, and $\mathrm{k}$ is a constant of proportionality. For any particular sensory continuum, $\varphi_{0}$ approximates the absolute threshold and $\beta$ is the exponent. For warmth, the exponent $\beta$ was found to equal 0.7 and the constant $\varphi_{0}$ was found to equal 1.0 millical $/ \mathrm{sec} \times \mathrm{cm}^{2}$. Equation 1 can be written in logarithmic form

$$
\log \psi=\beta \log \left(\varphi-\varphi_{0}\right)+\log k \text {. }
$$

In other words, a $\log$-log plot of sensory magnitude $\psi$ versus stimulus intensity $\left(\varphi-\varphi_{0}\right)$ produces a straight line whose slope is equal to the exponent $\beta$.

Three main questions are raised in the present study: (1) Does the psychophysical power law hold for various (constant) durations of exposure to an irradiant stimulus, and, if so, how do the parameters $k, \varphi_{0}$ and $\beta$ depend upon the value of the constant duration? (2) For any constant level of flux, how does apparent warmth change as a function of duration? (3) How does the level of apparent warmth aroused by different combinations of level of irradiance and duration of exposure correlate with the changes in skin temperature that occur during stimulation?

The maximum duration of stimulation used in this study was 12 sec. Ultimately, of course, it would be desirable to study the time-course of thermal sensation over minutes or even hours of stimulation, but the first 10 or $15 \mathrm{sec}$ have special interest. During this brief period, complicating effects of changes such as regulatory sweating and vasomotor action have not yet put in their appearance (Lipkin \& Hardy, 1954; Stolwijk \& Hardy, 1965); the time-course of the rise in superficial skin temperature can therefore be predicted (Stolwijk \& Hardy, 1965) solely on the basis of standard heat-flow equations and measurements of the optical and thermal properties of the skin. For any constant duration shorter than about $15 \mathrm{sec}$, the rise in superficial skin temperature is wholly proportional to the level of irradiant flux.

\section{Apparatus}

\section{METHOD}

The experiment was conducted in a large $(3.4 \times 4.3 \times 7.6 \mathrm{~m})$ air-conditioned test chamber. The air temperature was maintained at $20 \mathrm{deg} \mathrm{C}$ and the relative humidity at $30 \%$. The $\mathrm{S}$, blindfolded and clad only in briefs and socks, lay supine on a $0.8 \times 2.0 \mathrm{~m}$ bed (see Fig. 1). The ventral surface of the S's body was irradiated by eight General Electric T-3 quartz lamps, $40 \mathrm{~cm}$ long. The lamps were mounted in parabolic, cylindrical reflectors made of stainless steel and were placed $1.5 \mathrm{~m}$ above the bed. The spacing of the lamps provided a flux that was uniform within $10 \%$ over the surface of the S's body.

The fluctuations of the S's skin temperature were monitored continuously throughout each experimental session. For this

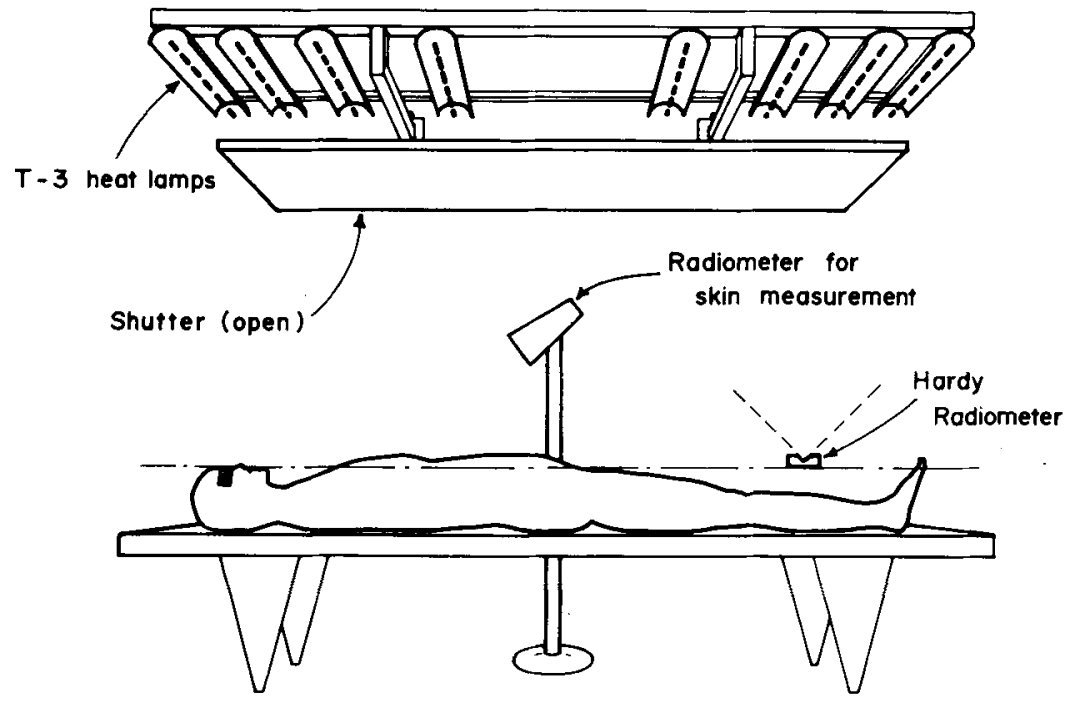

Fig. 1. The experimental setup. 
Table 1

The Voltages Across the Lamps (V), the Ascociated Incident Flux (H), and the Ascociated Absorbed Flux $(\varphi)$ in $\mathrm{millical} / \mathrm{sec} \times \mathrm{cm}^{2}$

\begin{tabular}{rcr}
$\mathrm{V}$ & $\mathrm{H}$ & $\varphi$ \\
\hline 80 & 3.65 & 3.36 \\
100 & 5.61 & 4.95 \\
120 & 7.80 & 6.69 \\
150 & 11.8 & 9.80 \\
200 & 19.5 & 15.5 \\
250 & 28.8 & 22.1 \\
\hline
\end{tabular}

purpose, a chopped-beam infrared radiometer, containing an internal reference cavity of constant temperature (described by Stolwijk \& Hardy, 1965), was mounted above and to the side of the S. The radiometer "viewed" the center of the S's chest from an angle $45 \mathrm{deg}$ from the perpendicular. The output from the radiometer was recorded graphically on a Honeywell "Electronik" 19 voltage recorder.

The radiant intensity from the quartz lamps was controlled by varying the voltage across the lamps. The relation between the voltage applied and the resultant level of flux emitted was determined by means of a standardized Hardy radiometer (Hardy, Wolff, \& Goodell, 1952) placed at the level of the S's skin. Of course, not all of the irradiant flux incident at the skin is actually absorbed; moreover, the proportion of the flux absorbed varies with the voltage applied to the lamps. Gagge, Rapp, and Hardy (1967) have computed the percentage of the flux absorbed for many levels of voltage applied to the T-3 quartz lamp (see J. C. Stevens \& Marks, 1967). Table 1 gives the six levels of voltage used in the present experiment, together with the corresponding irradiances and absorbed irradiances.

The duration of exposure to the radiation was controlled by means of a hand-operated aluminum shutter that moved on tracks $18 \mathrm{~cm}$ below the row of heat lamps.

\section{Procedure}

In the course of an experimental session, each of the six levels of irradiance was presented for each of five different durations ( 2 , $4,6,9$, or $12 \mathrm{sec}$ ). Thus, the stimulus ensemble consisted of 30 combinations of level and duration.

Three exposures (not judged) were given at the start of a session to acquaint the $S$ with the stimulus. These preliminary exposures also helped to determine a "baseline" skin temperature. Following the termination of each stimulus, the skin temperature was seen to drop to a fairly stable baseline; depending upon the level and the duration of the flux, this drop took anywhere from about $15 \mathrm{sec}$ to about $2 \mathrm{~min}$. Throughout the experiment a given stimulus was presented only after the skin temperature had returned to near "baseline" level. In this way a fairly constant level of sensitivity was presumably maintained, although drifts and perturbations of the baseline temperature appear from time to time, without obvious relation to the stimulation.

After the three preliminary exposures, one of the levels corresponding to 120 or $150 \mathrm{~V}$ (Table 1) was presented for either 4,6 , or $9 \mathrm{sec}$, and the $S$ assigned a number that seemed to him appropriate to stand for the degree of warmth experienced at the end of the exposure. This judgment was not counted. To the $\mathbf{3 0}$ subsequent exposures the $S$ attempted to assign numbers proportional to the degree of apparent warmth (the method of magnitude estimation). The order in which the various stimuli were presented was always irregular and was different in each session.

Each $\mathbf{S}$ served in two sessions, held on different days. The same set of stimuli was judged in both sessions. Sixteen white male adults, including the authors, served as Ss.

In addition, absolute thresholds were measured by a staircase procedure (S. S. Stevens, 1958) for five of the Ss who served in the main experiment. Each exposure of the stimulus lasted $3 \mathrm{sec}$. Two kinds of threshold were measured for each $S$ : the threshold for "warmth" and the threshold for "change." The measurement of the "warmth" threshold calls upon the $S$ to respond positively to a given presentation of the irradiant stimulus only if it arouses a definite quality of warmth. The measurement of the "change" threshold calls upon the $S$ to respond positively whenever the presentation of the irradiant stimulus arouses a change in sensation, even when the quality of warmth is not experienced. Both kinds of threshold were measured in a single session with each $\mathrm{S}$.

\section{RESULTS AND DISCUSSION}

\section{Apparent Warmth as a Function of Level of Flux}

The geometric means of the magnitude estimations are plotted in Fig. 2 as a function of the level of the irradiant flux. The five straight lines in these log-log coordinates demonstrate that for each of the five durations used, apparent warmth conforms to a power function of the form expressed in Equation 2. In other words, for any fixed duration up to about $12 \mathrm{sec}$, apparent warmth grows as a power function of the absorbed irradiant flux $\varphi$ minus the flux $\varphi_{0}$ that corresponds approximately to the absolute threshold for apparent warmth. In Fig. 2 the value of $\varphi_{0}$ chosen was $1.7 \mathrm{millical} / \mathrm{sec} \times \mathrm{cm}^{2}$. The exponent (slope) of the power function seems to be roughly the same over the shorter durations and to be a little greater at $9 \mathrm{sec}$ and $12 \mathrm{sec}$.

Note that the five functions in Fig. 2 have been displaced horizontally from one another. This was done in order to display the data for all stimulus durations in a readable manner. The levels of irradiance were, of course, the same from one duration to another.

The constants of the power functions were determined as follows. For each duration, a function of the form stated in Equation 2 was fitted by an iterative method of least squares (Marks, 1966; J. C. Stevens, 1967; J. C. Stevens \& Marks, 1967). For each of many possible values of $\varphi_{0}$ the constants $\beta$ and $\log k$

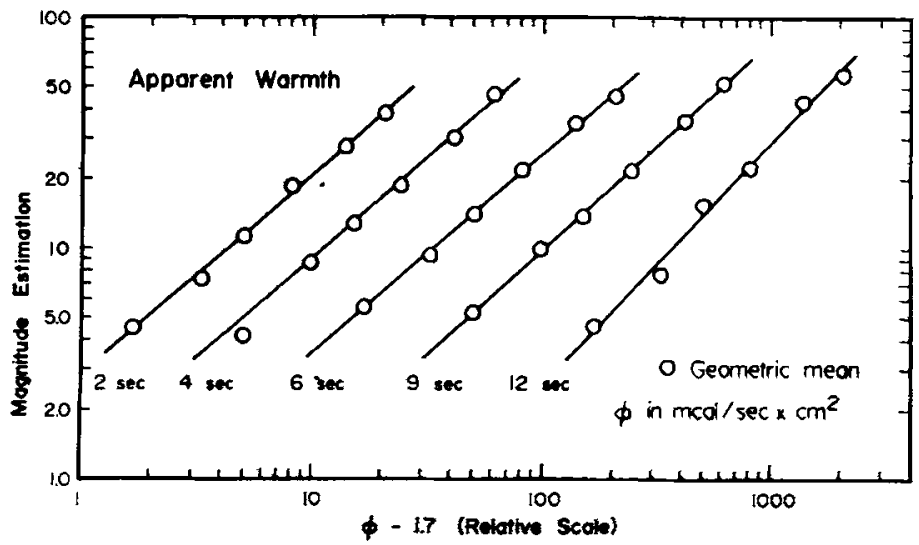

Fig. 2. Magnitude estimation of warmth as a function of the difference between the absorbed flux $\varphi$ and the flux $\left(1.7 \mathrm{millical} / \mathrm{sec} \times \mathrm{cm}^{2}\right)$ equal to the "effective" absolute threshold (see text). The parameter is the duration of the flux. For ease of inspection, the functions have been displaced from each other along the abscissa by arbitrary amounts (reading from left to right by factors of 1, 3,10, 30 , and 100 respectively). The actual tevels of flux were the same for each duration (see Table 1). 


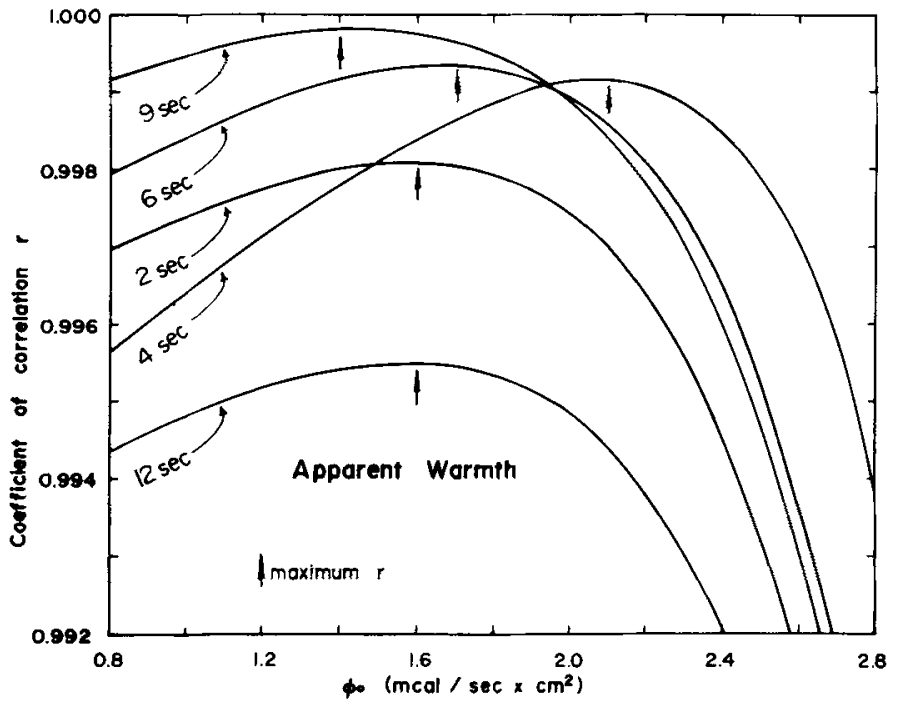

Fig. 3. How the Pearson correlation coefficient $r$ varies with the assumed value of the threshold nlux $\varphi_{0}$, for magnitude estimation of warmth. The parameter is the duration of the flux. were determined by least squares, operating on the logarithms of the geometric means and the logarithms of $\left(\varphi-\varphi_{0}\right)$. For each value of $\varphi_{0}$, a Pearson coefficient of correlation ( $r$ ) was also computed as an index of the goodness of fit of the straight line. Figure 3 shows how the correlation coefficient $r$ depends on the choice of $\varphi_{0}$ for the five different durations. Note that although the value of $r$ reaches a maximum at a particular value of $\varphi_{0}$, there is a region around this value over which $I$ changes very little with $\varphi_{0}$. The implication is that small differences in the value of $\varphi_{0}$ determined by the iterative method obviously should not be taken too seriously. Four of the five functions in Fig. 3 are nearly parallel; the function for the 4-sec duration peaks more sharply than the others and displays a maximal $r$ at a higher value of $\varphi_{0}$. The power functions plotted in Fig. 2 suggest that this difference may be due to the lowest point on the function for $4 \mathrm{sec}$, for when this point is not given its full weight the best-fitting straight line closely parallels the neighboring lines.

At any rate, there is no evidence that the value of $\varphi_{0}$ depends systematically on the duration. Table $2 \mathrm{~A}$ gives the values of $\varphi_{0}, \beta$, and $\log k$ for the maximum value of $r$. To the extent that $\varphi_{0}$ varied, it apparently did so at random. For this reason, the mean value of $\varphi_{0}, 1.7$, was adopted for the stimulus scale of Fig. 2. Table 2B shows the values of $\beta, \log \mathrm{k}$, and $\mathrm{r}$ under the assumption that $\varphi_{0}$ is constant at 1.7 . The value of $\beta$ is practically identical for the $2 \mathrm{sec}$ and $6 \mathrm{sec}$ durations, but is somewhat larger for the $4 \mathrm{sec}$ duration. Again, the functions plotted in Fig. 2 suggest that this difference for $4 \mathrm{sec}$ is due to the lowest point on the function. When this point is disregarded, the exponent is quite close to those for $2 \mathrm{sec}$ and $6 \mathrm{sec}$. In any case, the effect on $\beta, \log \mathrm{k}$, and $\mathrm{r}$ of selecting a value of 1.7 for $\varphi_{0}$, rather than the "best" values, is very small.
Figure 4 shows how the constants $\beta$ and $\log k$ vary with the choice of $\varphi_{0}$. Over wide portions of their length the functions for various durations parallel each other closely. This fact implies that the exact choice of $\varphi_{0}$ will have negligible effect on the relative values of $\beta$ and $\log k$. The higher the value of $\varphi_{0}$ the lower will be all the values of $\beta$ and the higher all the values of $\log k$. In other words, relative to each other the slopes and positions of the straight lines in Fig. 2 may be regarded as determined with reasonable confidence. Thus the rise in the value of $\beta$ at longer durations, seen in Table $2 \mathrm{~B}$ and in Fig. 2 , is independent of the exact choice of $\varphi_{0}$.

Actually, a value of 1.7 for $\varphi_{0}$ is larger than might be expected in the light of the earlier study of thermal irradiation of the back (J. C. Stevens \& Marks, 1967). In that study, $\varphi_{0}$ turned out to be 1.0 and $\beta$ to be 0.7 . On the other hand, a similar experiment by Herget, Granath, and Hardy (1941) yielded a $\varphi_{0}$ of 1.7 with $\beta$ equal to 0.45 (see J. C. Stevens \& Marks, 1967, p. 618). Direct measurements of the absolute threshold for warmth vary from about 0.3 (Hardy \& Oppel, 1937) to $1.6 \mathrm{millical} / \mathrm{sec} \mathrm{x} \mathrm{cm}$ (Chrenko, 1964), depending upon a variety of factors, such as the psychophysical method used, the area and location of stimulation, the skin temperature, and the "set" of the S. In order to learn how closely the inferred value. of 1.7 obtained by the iterative method corresponds to direct measurement of absolute sensitivity under reasonably comparable experimental conditions, we now turn to the measurements of the absolute threshold for "warmth" and "change."

\section{Absolute Sensitivity to Warmth}

Table 3 gives the absolute thresholds for "warmth" and "change" measured in five Ss. Although the threshold varied

Table 2

The Computed Constants of the Functions for Apparent Warmth for Five Durations: Exponent $(\beta)$, Intercept Constant $(\log k)$, "Effective" Threshold $\left(\varphi_{0}\right)$, and Pearson Coefficient of Correlation ( $r$ )

A. The values of $\beta, \log k$, and $\mathbf{r}$ that correspond to the "best" values of $\varphi_{\mathbf{0}}$. B. The values of $\beta, \log k$, and $r$ that correspond to $\varphi_{0}$ equal to 1.7 .

A

$\begin{array}{cccc}\begin{array}{c}\text { Duration } \\ (\mathrm{sec})\end{array} & \beta & \log \mathrm{k} & \varphi \\ 2 & 0.88 & 0.43 & 1 \\ 4 & 0.85 & 0.54 & 2 . \\ 6 & 0.86 & 0.55 & 1.7 \\ 9 & 0.96 & 0.45 & 1.4 \\ 12 & 1.06 & 0.38 & 1\end{array}$

\begin{tabular}{|c|c|c|c|c|c|}
\hline & & & B & & \\
\hline I & $\begin{array}{l}\text { Duration } \\
\quad(\mathrm{sec})\end{array}$ & $\beta$ & $\log k$ & $\varphi_{0}$ & $r$ \\
\hline 0.9981 & 2 & 0.87 & 0.45 & 1.7 & 0.9980 \\
\hline 0.9992 & 4 & 0.93 & 0.44 & 1.7 & 0.9987 \\
\hline 0.9993 & 6 & 0.86 & 0.55 & 1.7 & 0.9993 \\
\hline 0.9998 & 9 & 0.91 & 0.52 & 1.7 & 0.9996 \\
\hline 0.9955 & 12 & 1.04 & 0.41 & 1.7 & 0.9955 \\
\hline
\end{tabular}




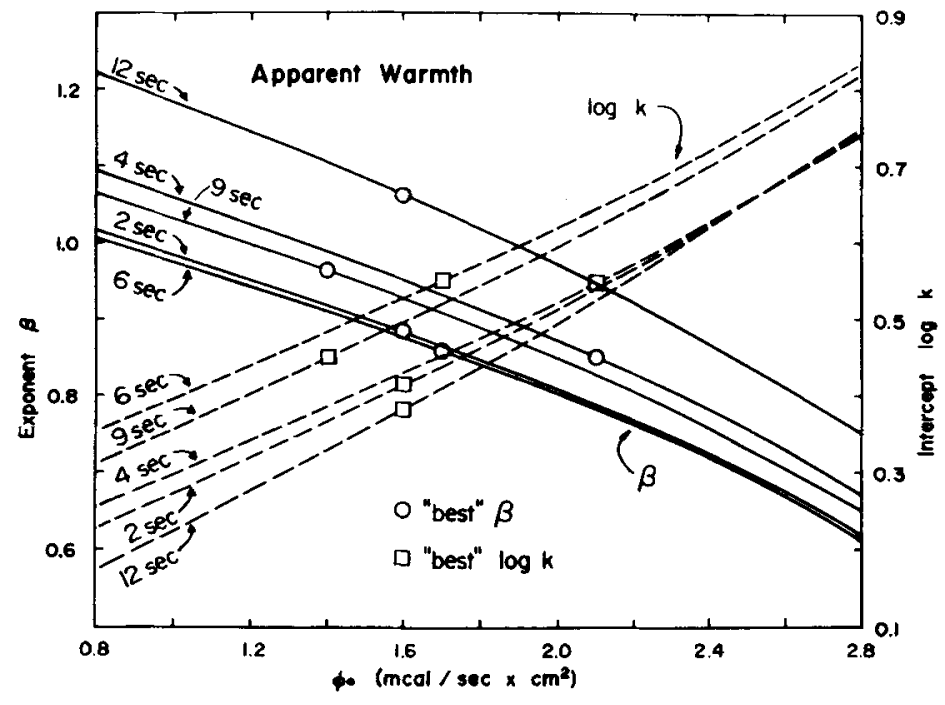

Fig. 4. How the constants $\beta$ and $\log k$ vary with the assumed value of the threshold flux $\varphi_{0}$. The parameter is the duration of the flux. The circles and squares respectively mark the values of $\beta$ and $\log k$ for the values of $\varphi_{0}$ that yielded the maximal Pearson correlation coefficients (listed in Table 2 and shown in Fig. 3).

substantially from one $S$ to another, four of the five Ss yielded a larger threshold for "warmth" than for "change." The mean

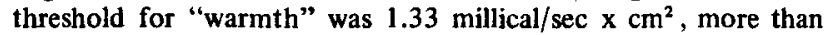
$50 \%$ larger than the mean threshold for "change" $(0.85)$. The value of $\varphi_{0}$ inferred from the magnitude estimates of warmth (1.7) is about 25\% larger than the absolute threshold measured for "warmth." It is the threshold for "warmth" that would seem to be the one relevant to the psychophysical function as expressed in Equation 2.

The much larger difference between the thresholds for "warmth" and for "change" may help to explain some of the variation among the measured values of the absolute threshold that have been reported from time to time. It is possible, for example, that the Ss examined by Hardy and Oppel (1937) were responding to "change," whereas those examined by Chrenko (1964) were responding to qualitative "warmth."

\section{Apparent Warmth as a Function of Duration}

The geometric means of the magnitude estimations are plotted also in Fig. 5, here as a function of the duration of the flux. The trend of each function is reasonably obvious from the plotted points themselves, but the curves were actually drawn so that they pass through points predicted from the power functions of Fig. 2

The following features of Fig. 5 are noteworthy. At every level of flux tested, the apparent warmth changes very little with duration. At the highest level of flux the apparent warmth increased continuously with duration, but the total increase from $2 \mathrm{sec}$ to $12 \mathrm{sec}$ amounted to only $50 \%$. At intermediate levels, the apparent warmth rose very slightly at first, then remained practically constant. At the lowest levels, however, warmth increased slightly at first and then actually decreased slightly. Nevertheless, the overall picture shows that, over relatively short-term exposures the degree of warmth experienced is, in the psychophysical sense, primarily related to the level of the irradiant flux and only secondarily related to the duration of the flux. This poses an interesting problem, because the thermal response of the

Table 3

Measured Absolute Thresholds for "Warmth" and "Change" in millical/sec $\mathrm{x} \mathrm{cm}{ }^{2}$

\begin{tabular}{lll} 
Observer & "Change" & "Warmth" \\
\hline HO & 0.31 & 0.74 \\
AA & 0.55 & 0.86 \\
WH & 0.78 & 2.38 \\
JS & 1.26 & 1.23 \\
LM & 1.34 & 1.46 \\
\hline
\end{tabular}

skin itself is closely and directly related to both the level and the duration of the flux.

\section{Relation of Apparent Warmth to Skin Temperature}

The measurement of the changes in skin temperature that took place throughout the experimental session involved certain complications. The radiometer used for this purpose inevitably registers not only the radiation emitted by the skin but also the radiation from the lamps that is reflected by the skin. The contribution of the reflected radiation to the total apparent rise in skin temperature varies with level of the irradiant stimulus for any one $S$, and from $S$ to $S$ for any given level of stimulation. It was nevertheless possible to estimate the actual rise in skin temperature produced by any stimulus presentation. A typical recording from the radiometer showed an early rapid rise, due primarily to reflected radiation, followed by a slower rise, due wholly to rising skin temperature. At the cessation of stimulation the recordings showed an early rapid decline, due primarily to the removal of reflected radiation, followed by a slower decline. By means of extrapolations one can estimate the portion of the apparent rise due to change in skin temperature alone.

In Fig. 6 the mean change in skin temperature is plotted as a function of duration for each level of irradiance. (The changes produced when the skin was irradiated for $2 \mathrm{sec}$ by 3.36 and 4.95 millical/sec $\mathrm{x} \mathrm{cm}^{2}$ were too small to be measured with confidence and are therefore omitted from Fig. 6.) For each level of irradiance the superficial skin temperature rose continuously with duration. Clearly the time-course for the sensation of warmth (Fig. 5) does not correspond very closely to the thermal changes at the surface of the skin. It is, of course, unlikely that the receptors that mediate warmth would be located at the most superficial level of skin. But what about the thermal changes at deeper levels of the skin?

In order to examine changes deeper in the skin, the time-course of cutaneous and subcutaneous tissue temperatures was simulated by a procedure contributed by Stolwijk and Hardy (1965). Their model divides the skin (to a depth of $10.8 \mathrm{~mm}$ ) into eight layers: two superficial horny layers and two basal layers (each layer 0.05 $\mathrm{mm}$ thick), followed by three subcutaneous vascular layers (each $0.2 \mathrm{~mm}$ thick), and finally a deep fatty layer (10 mm thick). At any moment of time, the heat absorbed in any layer $n$ is proportional to the irradiant energy absorbed in that layer $\left(E_{n}\right)$ plus the difference between its temperature $\left(T_{n}\right)$ and the temperature at the next most superficial layer $\left(T_{n-1}\right)$ plus the difference between $T_{n}$ and the temperature at the next deepest layer $\left(T_{n+1}\right)$. The general equation for the rate of change of temperature at layer $n \frac{\left(d T_{n}\right)}{d t}$ is 


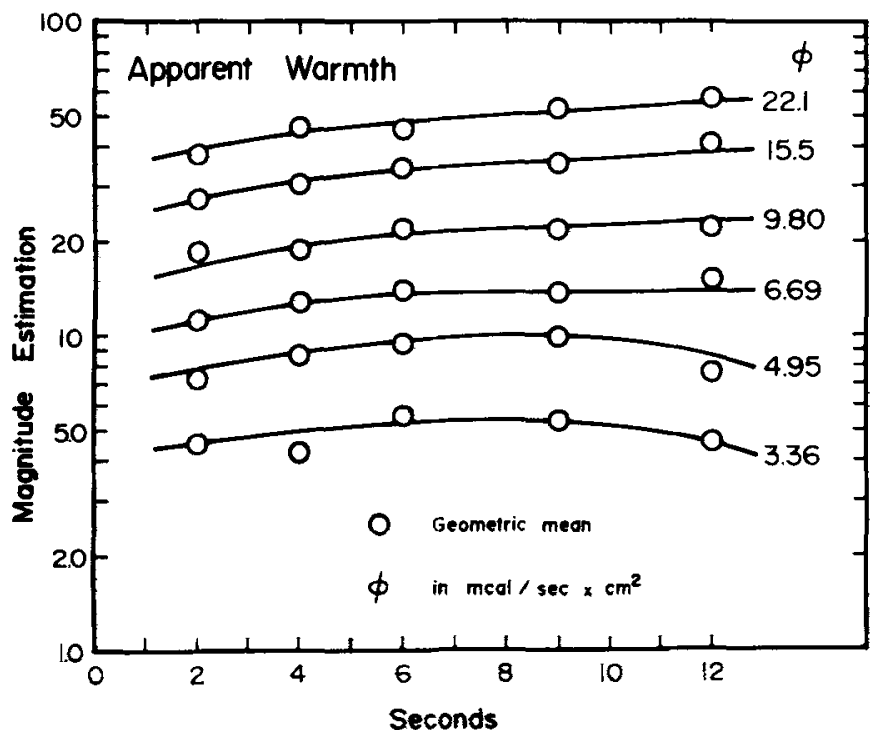

Fig. 5. Magnitude estimation of warmth as a function of the duration of the flux. The parameter is the level of the flux. The lines pass through points predicted by the power functions plotted in Fig. 2.

$$
\frac{d T_{n}}{d t}=\frac{E_{n}+\frac{k_{n, n-1}}{\Delta x_{n, n-1}}\left[T_{n-1}-T_{n}\right]+\frac{k_{n, n+1}}{\Delta x_{n, n+1}}\left[T_{n+1}-T_{n}\right]}{\Delta x_{n} \rho_{n} c_{n}}
$$

where $\Delta x_{n}$ is the thickness of layer $n$,

$\rho_{n}$ is the density of layer $n$,

$c_{n}$ is the specific heat of layer $n$,

$k_{n, n-1}$ and $k_{n, n+1}$ are the thermal conductivities between the centers of layers $n$ and $n-1$ and between the centers of layers $n$ and $n+1$, and

$\Delta x_{n, n-1}$ and $\Delta x_{n, n+1}$ are the distances between the centers of layers $n$ and $n-1$ and between the centers of layers $n$ and $\mathrm{n}+1$.

Table 4 gives the values of the thermal constants for each of the eight layers. The radiant heat absorbed in layer $\mathrm{n}$ is given by the equation

$$
E_{n}=I_{0}\left(1-e^{-\Delta x r}\right)
$$

where $I_{0}$ is the radiant flux that $f$ nters the layer and $r$ is the absorption coefficient. Note that Table 4 gives a single value of $r$ $(22 / \mathrm{cm})$ for each layer of skin. In fact, the value of $\mathrm{r}$ probably varies somewhat from layer to layer and also with the level of flux. This is so because the degree to which the irradiant flux penetrates the skin depends upon the wavelength of the flux, and thus also upon the color temperature of and the voltage across the lamps (see J. C. Stevens \& Marks, 1967). In order to simplify the computations, however, a single average value of $r$ was used.

The constants in Table 4 were used to generate a heat-flow equation for each layer of skin. In the following equations, $T_{a}$ is the ambient temperature and $\varphi$ is the absorbed irradiance (irradiant flux minus reflected flux) in millical/sec $x \mathrm{~cm}^{2}$.

Table 4

Physical Properties of Superficial and Subcutaneous Layers of Skin (from Stolwijk \& Hardy, 1965)

\begin{tabular}{llllll} 
Layer & $\begin{array}{c}\Delta \mathrm{x} \\
(\mathrm{cm})\end{array}$ & $\begin{array}{c}\rho \\
\left(\mathrm{g} / \mathrm{cm}^{3}\right)\end{array}$ & $\begin{array}{c}\mathrm{c} \\
(\mathrm{cal} / \mathrm{g} \\
\left.\mathrm{x}^{\circ} \mathrm{C}\right)\end{array}$ & $\begin{array}{c}\mathrm{k} \\
(\mathrm{cal} / \mathrm{cm} \mathrm{x} \\
\left.\mathbf{s e c ~}{ }^{\circ} \mathrm{C}\right)\end{array}$ & $\begin{array}{c}\mathrm{I} \\
(\mathrm{I} / \mathrm{cm})\end{array}$ \\
\hline 1 & 0.005 & 1.2 & 0.86 & 0.0005 & 22.0 \\
2 & 0.005 & 1.2 & 0.86 & 0.0005 & 22.0 \\
3 & 0.005 & 1.2 & 0.86 & 0.0009 & 22.0 \\
4 & 0.005 & 1.2 & 0.86 & 0.001 & 22.0 \\
5 & 0.02 & 1.2 & 0.86 & 0.001 & 22.0 \\
6 & 0.02 & 1.2 & 0.86 & 0.001 & 22.0 \\
7 & 0.02 & 1.2 & 0.86 & 0.001 & 22.0 \\
8 & 1.0 & 0.92 & 0.55 & 0.0004 & 22.0 \\
\hline
\end{tabular}

$\frac{\mathrm{dT}}{\mathrm{dt}} \mathrm{l}=0.0324\left(\mathrm{~T}_{\mathrm{a}}-\mathrm{T}_{1}\right)+19.4\left(\mathrm{~T}_{2}-\mathrm{T}_{1}\right)+0.0202 \varphi$

$\frac{\mathrm{dT}}{\mathrm{dt}} 2=19.4\left(\mathrm{~T}_{1}-\mathrm{T}_{2}\right)+25.0\left(\mathrm{~T}_{3}-\mathrm{T}_{2}\right)+0.0186 \varphi$

$\frac{\mathrm{dT}}{\mathrm{dt}} 3=25.0\left(\mathrm{~T}_{2}-\mathrm{T}_{3}\right)+36.8\left(\mathrm{~T}_{4}-\mathrm{T}_{3}\right)+0.016 .5 \varphi$

$\frac{\mathrm{dT}}{\mathrm{dt}} \mathrm{A}=36.8\left(\mathrm{~T}_{3}-\mathrm{T}_{4}\right)+15.5\left(\mathrm{~T}_{5}-\mathrm{T}_{4}\right)+0.01435 \varphi$

$\frac{\mathrm{dT}}{\mathrm{dt}} 5=3.87\left(\mathrm{~T}_{4}-\mathrm{T}_{5}\right)+2.42\left(\mathrm{~T}_{6}-\mathrm{T}_{5}\right)+0.0110 \varphi$

$\frac{\mathrm{dT}}{\mathrm{dt}} 6=2.42\left(\mathrm{~T}_{5}-\mathrm{T}_{6}\right)+2.42\left(\mathrm{~T}_{7}-\mathrm{T}_{6}\right)+0.00704 \varphi$

$\frac{\mathrm{dT}}{\mathrm{dt}} 7=2.42\left(\mathrm{~T}_{6}-\mathrm{T}_{7}\right)+0.0387\left(\mathrm{~T}_{8}-\mathrm{T}_{7}\right)+0.00471 \varphi$

$\frac{\mathrm{dT}}{\mathrm{dt}} 8=0.00157\left(\mathrm{~T}_{7}-\mathrm{T}_{8}\right)+0.00393+0.000342 \varphi$

This model assumes unidimensional (vertical) heat flow only. That is, lateral heat flow is considered to be negligible. Since in the present experiment the entire front surface of the body was irradiated, the assumption of unidimensional heat flow seems reasonable. Note, however, that Equations 5-12 are of little use in simulating thermal changes in the skin when small areas are stimulated.

In order to simulate the conditions of the present experiment, $T_{a}$ was set to equal $20.0 \mathrm{deg} C$ and the initial temperature of Layer 1 was set to equal $32.0 \mathrm{deg} C$. It is assumed that just prior to stimulation the eight layers of skin were in thermal equilibrium. Thus the initial thermal gradient was calculated by setting $\frac{\mathrm{dT}_{\mathrm{n}}}{\mathrm{dt}}$ equal to zero in each equation (5-12) and solving for the value of $T_{n}$. Under the assumption that the initial heat loss to the environment equalled $6.0 \mathrm{kcal} / \mathrm{m}^{2} \times \mathrm{hr} \times \operatorname{deg} \mathrm{C}\left(0.000167 \mathrm{cal} / \mathrm{cm}^{2} \mathrm{x} \mathrm{sec}\right.$ $x$ deg C) (see Gagge, Rapp, \& Hardy, 1964), the constant metabolic input from the deepest layer into Layer 8 was computed to be $72.0 \mathrm{kcal} / \mathrm{m}^{2} \times$ hr $\left(0.002 \mathrm{cal} / \mathrm{cm}^{2} \times \mathrm{sec}\right)$.

For each level of stimulation the appropriate value of $\varphi$ (see Table 1) was entered into the eight heat-flow equations. The rise in the temperatures of the various levels as a function of duration was calculated on an IBM 1130 digital computer by means of the method of finite differences. The simultaneous integrations were done at intervals of $0.01 \mathrm{sec}$ (simulated time). The results for Layer 1 (depth $0.0025 \mathrm{~cm}$ ) are shown by the curves in Fig. 6 . There is fairly good agreement between the results of the simulation and the experimentally obtained average rises in superficial skin temperature. 


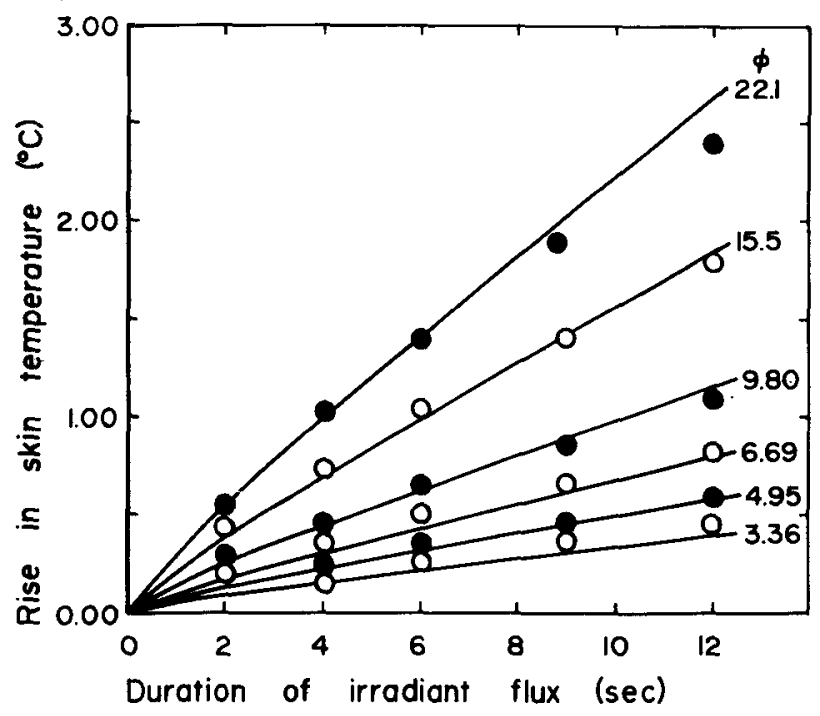

Fig. 6. Arithmetic means of the changes in superficial skin temperature as a function of duration for the six levels of absorbed irradiance $(\varphi)$. The lines are predicted changes (see text) in the temperature of Layer 1 (depth of $0.025 \mathrm{~mm}$ ).

Figure 7 shows the theoretical rise in the temperature of Layer 5 (depth of $0.30 \mathrm{~mm}$ ) and of Layer 7 (depth of $0.70 \mathrm{~mm}$ ). The rises in tissue temperature are shown for three levels of stimulation used in the present experiment: the lowest level, an intermediate level, and the highest level. At both depths below the surface and for all three levels of irradiance, tissue temperature rises continuously with duration. The shapes of all of the curves are similar to the shapes of the temperature-duration curves for the surface of the skin. It may be concluded, therefore, that subcutaneous tissue temperature per se, like surface temperature, is not a good correlate of apparent warmth. When the duration of the exposure is brief (less than about $15 \mathrm{sec}$ ) and constant, the skin temperature correlates well with apparent warmth; but the correlation breaks down when the duration of the exposure is varied.

The magnitude estimation of warmth shows that, up to at least $12 \mathrm{sec}$, the level of perceived warmth is relatively independent of

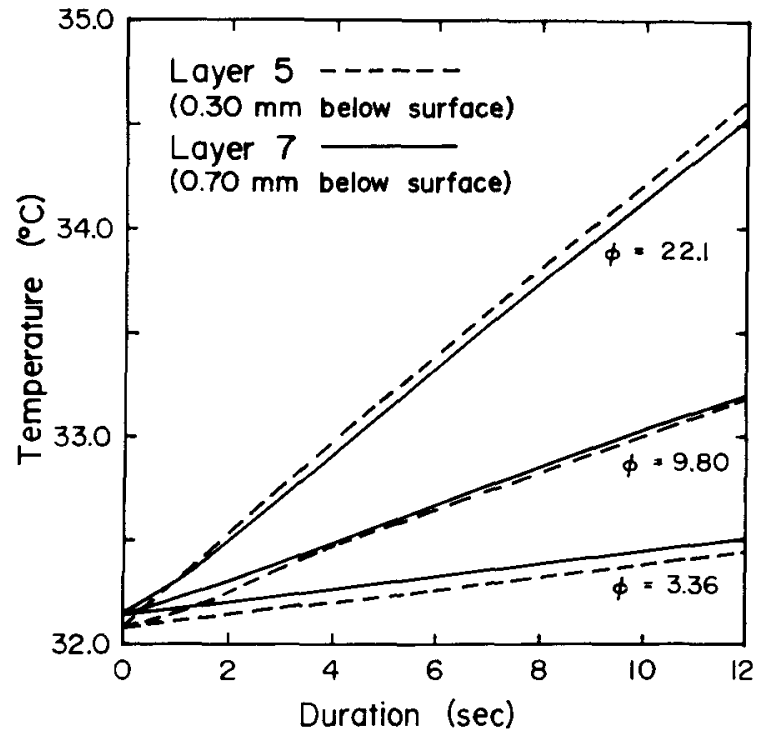

Fig. 7. Theoretical changes in temperature of Layer 5 (depth of $0.30 \mathrm{~mm}$ ) and of Layer 7 (depth of $\mathbf{0 . 7 0} \mathrm{mm}$ ) as functions of duration for three levels of absorbed irradiance $(\varphi)$.

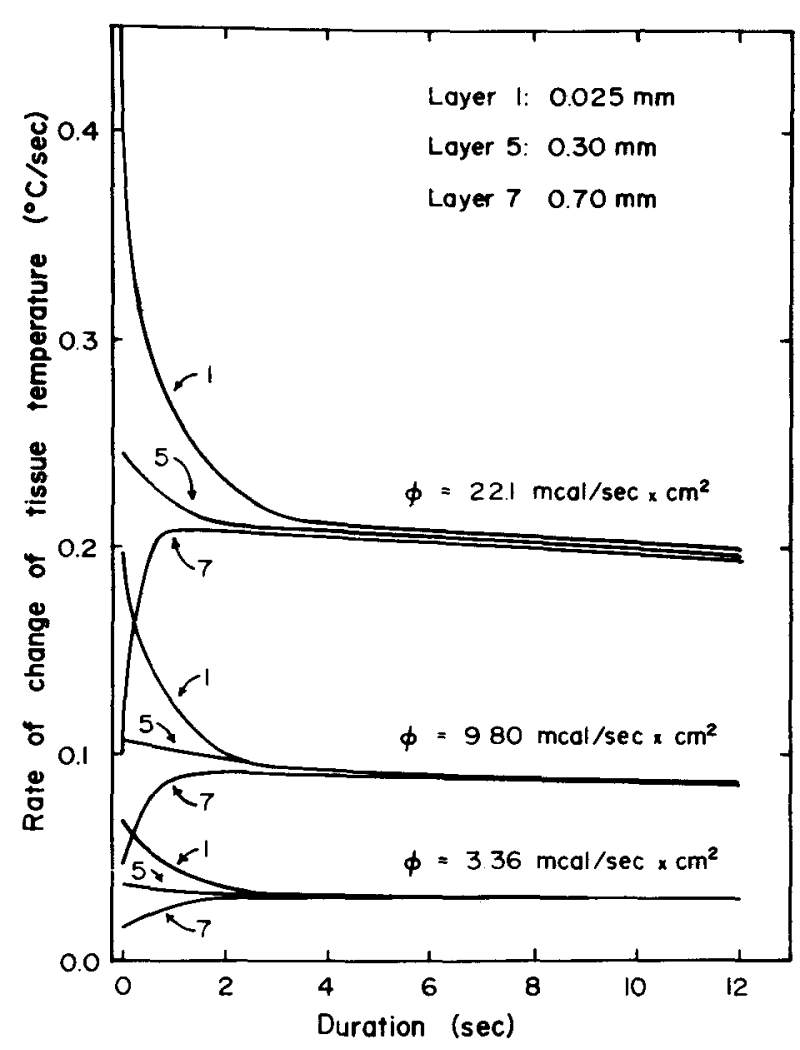

Fig. 8. Rate of change of temperature of Layer 1 (depth of $0.025 \mathrm{~mm}$ ), Layer 5 (depth of $0.30 \mathrm{~mm}$ ), and Layer 7 (depth of $0.70 \mathrm{~mm}$ ) as functions of duration for three levels of absorbed irradiance $(\varphi)$.

duration. True, warmth for the highest levels of stimulation rises somewhat with duration; warmth for the lowest levels rises at first, then falls. But tissue temperature both at the surface and at lower levels rises markedly and continuously with duration for all levels of stimulation.

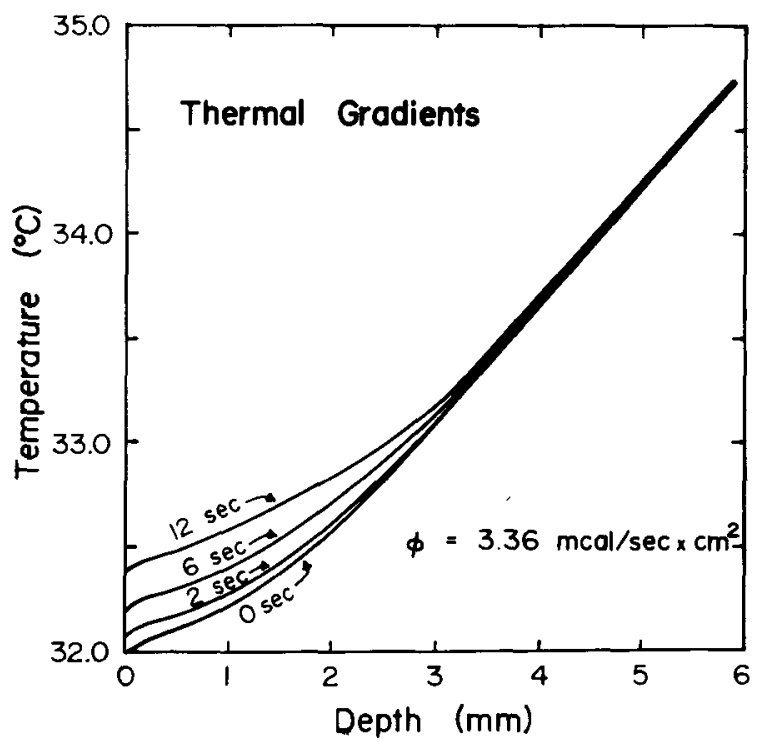

Fig. 9. Theoretical temperature as a function of depth at four points in time: just prior to stimulation $(0 \mathrm{sec})$, and 2,6 , and $12 \mathrm{sec}$ after the onset of stimulation. The level of absorbed irradiance was $3.36 \mathrm{millical} / \mathrm{sec} \mathrm{x} \mathrm{cm}^{2}$. 


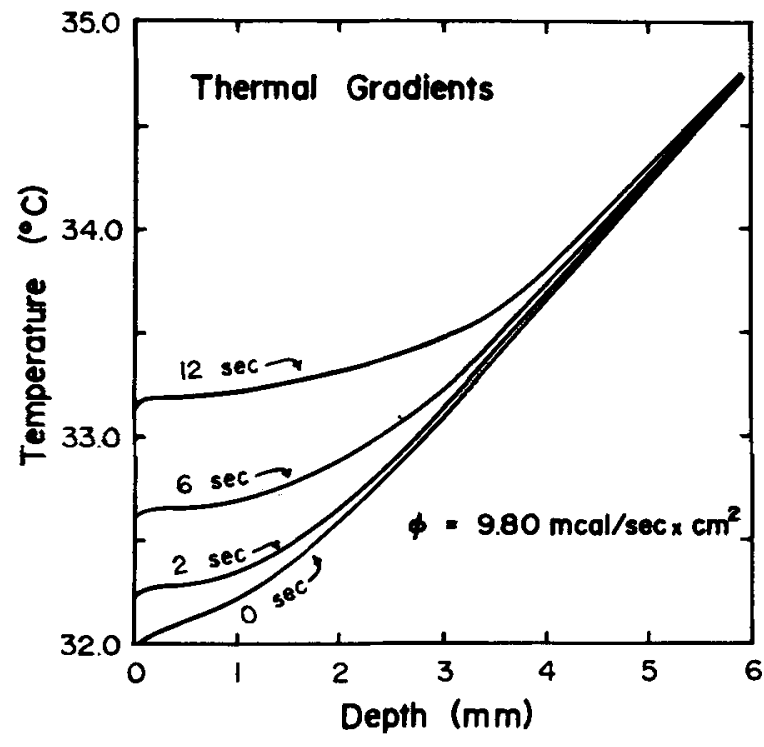

Fig. 10. Theoretical temperature as a function of depth at four points in time: just prior to stimulation $(0 \mathrm{sec})$, and 2,6 , and $12 \mathrm{sec}$ after the onset of stimulation. The level of absorbed irradiance was $9.80 \mathrm{millical} / \mathrm{sec} \mathrm{x} \mathrm{cm}$.

\section{Other Possible Correlates of Apparent Warmth}

Rate of change. The question arises whether any single factor other than tissue temperature might correlate consistently with the level of perceived warmth. One possibility is the rate of change of tissue temperature. Figure 8 shows how the rate of -change of tissue temperature varies with duration at a depth $0.025 \mathrm{~mm}$ below the surface (Layer 1), at a depth of $0.3 \mathrm{~mm}$ (Layer 5), and at a depth of $0.7 \mathrm{~mm}$ (Layer 7) for three levels of irradiant stimulation. After about $4 \mathrm{sec}$ the rate of change is nearly constant with duration for all three depths. In fact, there may be a depth (between the centers of Layers 5 and 7) at which rate of change is nearly constant over the entire span of duration. At first glance, therefore, it might appear that rate of change correlates well with degree of apparent warmth. But although rate of change is nearly constant over time, it does decrease, to a degree, with time. This is most apparent for the highest level of irradiation. Since apparent warmth for the highest level of stimulation increased somewhat with time, rate of change would also have had to increase somewhat with time in order for apparent warmth and rate of change to correlate well. But an increasing rate of change would imply that tissue temperature itself would increase as a positively accelerated function of time. This would seem to be unlikely.

Thermal gradient. Another possible correlate is the temperature gradient of the skin. The skin simulation makes it possible to examine the temperature gradient from the surface to a depth of $5.775 \mathrm{~mm}$ as a function of level and duration of irradiation. Figures 9-11 show, for three levels of absorbed irradiance, the thermal gradients just prior to stimulation, and 2,6 , and $12 \mathrm{sec}$ after the onset of stimulation. Clearly, for any fixed level of stimulation the thermal gradient changes its shape over time continuously, and the change in shape looks similar from one level of stimulation to another. Thermal gradient does not, therefore, correlate better with apparent warmth than does tissue temperature.

Temperature difference. Still another possible correlate, similar to temperature gradient, is the difference between the temperatures at two depths in the skin. This possibility is suggested by the work of Hendler, Hardy, and Murgatroyd (1963), who measured absolute thresholds with infrared and microwave stimulation for a number of stimulus durations. (Microwaves penetrate into the skin much more readily than infrared rays.) They examined a number of possible correlates to warmth. The following were found unsatisfactory: rise in tissue temperature $(\Delta T)$, rate of change of tissue temperature $(d T / d t)$, rate of rate of

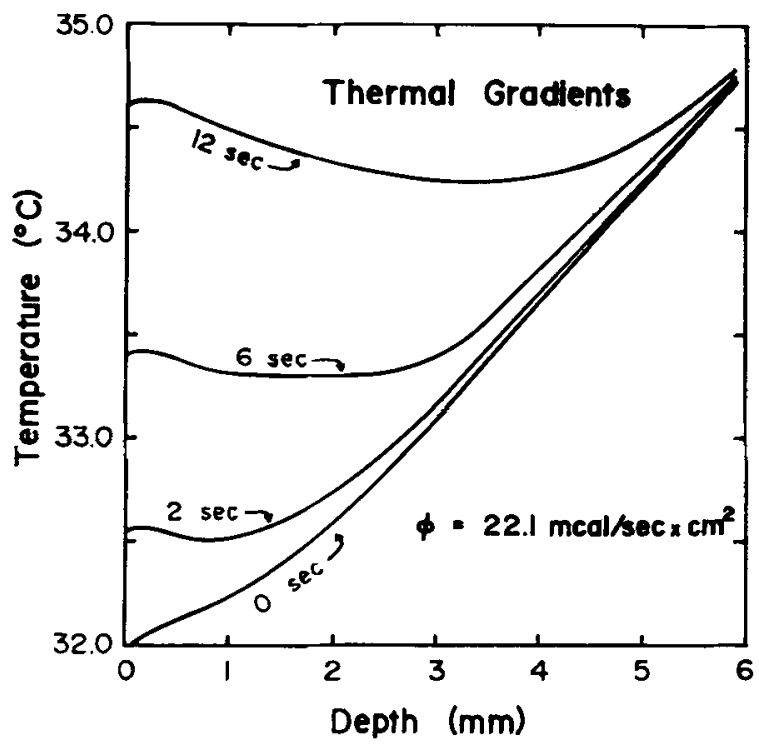

Fig. 11. Theoretical temperature as a function of depth at four points in time: just prior to stimulation ( 0 sec), and 2,6, and $12 \mathrm{sec}$ after the onset of stimulation. The level of absorbed irradiance was 22.1 millical $/ \mathrm{sec} \times \mathrm{cm}^{2}$.

change of temperature $\left(d^{2} T / d t^{2}\right)$, and thermal gradient ( $\left.d T / d x\right)$. It was noted, however, that the change in the difference between the temperature $0.2 \mathrm{~mm}$ and the temperature $1.0 \mathrm{~mm}$ below the surface of the skin was generally the same for both infrared and microwave stimulation at the various durations examined. Hendler, Hardy, and Murgatroyd concluded that the difference between the temperatures 0.2 and $1.0 \mathrm{~mm}$ beneath the skin surface may provide a correlate to warmth.

Figure 12 shows the change in the difference between the temperatures 0.2 and $1.0 \mathrm{~mm}$ beneath the skin surface as a function of duration for each level of absorbed irradiance used in the present experiment. For all six levels the curves increase over the first $6 \mathrm{sec}$, then remain nearly constant. This result is strikingly similar to the way apparent warmth varies with duration (Fig. 5). But although the similarity between these two sets of functions is great, the correlation between temperature difference and apparent warmth is not perfect. In particular, the changes in

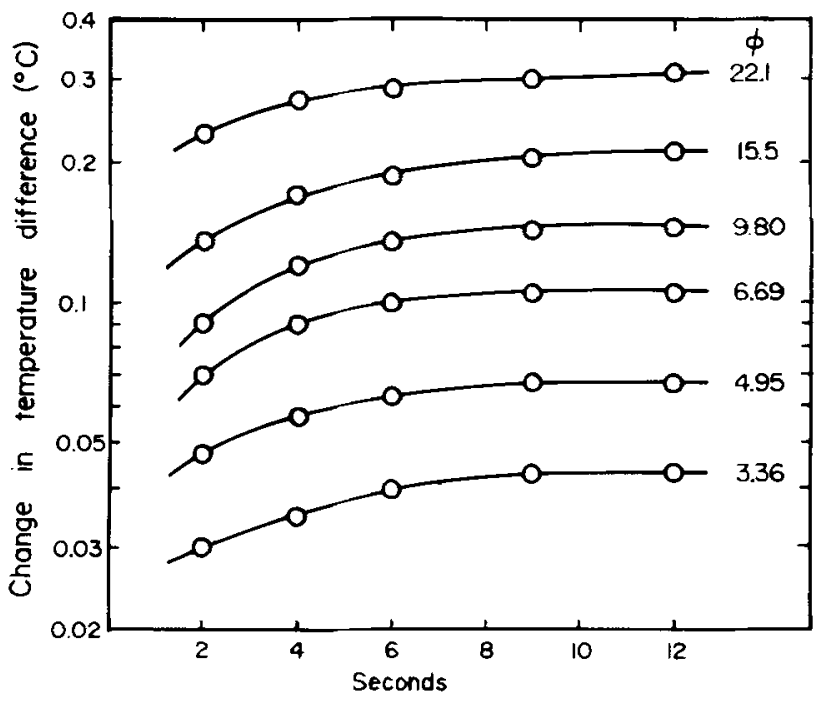

Fig. 12. Change in the difference between the temperature $0.2 \mathrm{~mm}$ and the temperature $1.0 \mathrm{~mm}$ below the surface of the skin as a function of duration of the irradiant flux. The parameter is the level of the flux $(\varphi)$. 


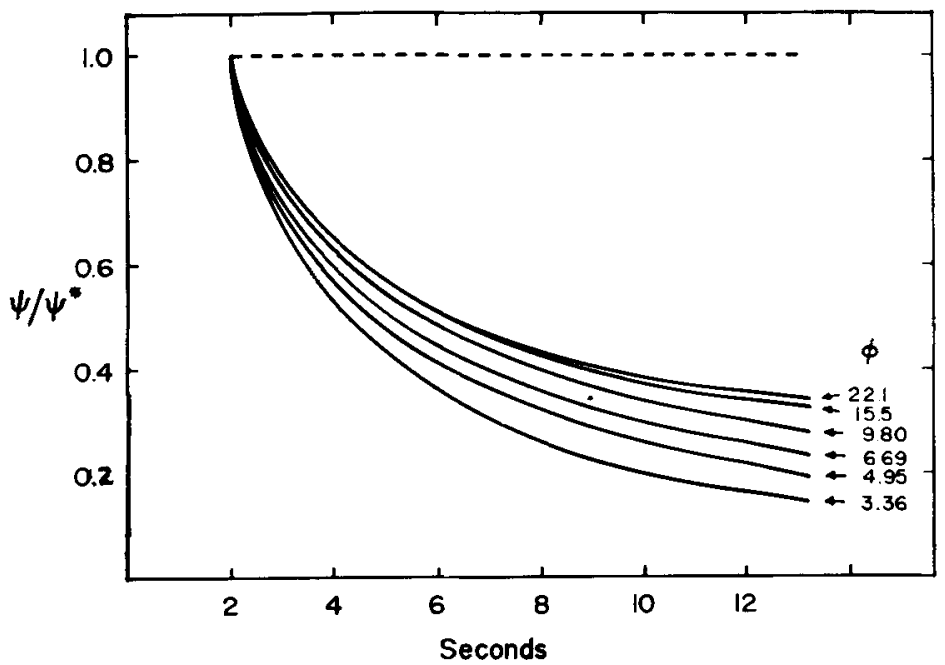

Fig. 13. The ratio of level of perceived warmth $(\psi)$ to level of warmth that would be predicted solely on the basis of rise in skin temperature $\left(\psi^{*}\right)$ as a function of duration for the six levels of absorbed irradiance $(\varphi)$. The dashed line shows how $\left(\psi / \psi^{*}\right)$ would vary if no adaptation occurred.

temperature difference shown in Fig. 12 imply that the exponent of the power function relating warmth and level of irradiance should remain about constant, or perhaps even decrease slightly, as duration increases. In fact, Fig. 2 shows that the exponent of the power function increased for the longer durations. At present the evidence is far from conclusive that temperature difference is the critical variable involved in determining level of perceived warmth.

\section{Apparent Warmth and Adaptation}

It appears that change in skin temperature, rate of change of skin temperature, and temperature gradient all fail to correlate consistently with the way in which perceived warmth depends upon the level and the duration of the irradiation. The change in the difference between the temperature $0.2 \mathrm{~mm}$ and the temperature $1.0 \mathrm{~mm}$ below the skin surface correlates with degree of perceived warmth to a first-order approximation, but the correlation is not good enough to be conclusive. If temperature difference turns out not to be the critical variable, then it may be necessary to appeal to some kind of adaptation in the sense organ. Eijkman and Vendrik (1961, 1968), for example, reported threshold data for warmth that are compatible with the notion of a highly adapting system. They found that the rise in tissue temperature necessary to produce a threshold sensation increased with the duration of an irradiant (microwave) stimulus. The evidence from the present experiment that the value of the "effective" threshold $\varphi_{0}$ remained constant as duration varied is similar to the results reported by Eijkman and Vendrik and by Hendler, Hardy, and Murgatroyd (1963). The rise in skin temperature that corresponds to the "effective" threshold $\left(\varphi_{0}=1.7 \mathrm{millical} / \mathrm{sec} \mathrm{x} \mathrm{cm}{ }^{2}\right.$ ) was computed to be $0.04 \mathrm{deg} \mathrm{C}$ for a 2 -sec exposure, but rose to $0.20 \mathrm{deg} C$ for a 12 -sec exposure.

Kenshalo, Holmes, and Wood (1968) suggested adaptation to explain the effect that raie of stimulus change exerts on the thresholds for warmth and cold. For rates of change above a certain value $(0.1 \mathrm{deg} \mathrm{C} / \mathrm{sec})$ the threshold was independent of the rate of change. Below that value, larger changes of stimulator temperature were necessary as rate of change decreased. In another experiment, Kenshalo and Scott (1966) called upon Ss to adjust the temperature of a stimulator in order to maintain a just-detectable sensation of warmth or cold. Adaptation was measured as the change in temperature of the stimulator, over time, that was required to maintain a "threshold" sensation.

The inferred effect of adaptation on apparent warmth in the present study is depicted in Fig. 13. On the ordinate is plotted apparent warmth $\psi$ as a fraction of the level of warmth that would be expected if no adaptation occurred $\psi^{*}$, i.e., if warmth depended on skin temperature only. The rise in skin temperature (Layer 1) was computed for each level and duration of irradiation $\varphi$. The next computation was the level of irradiation $\varphi^{*}$ that would, in $2 \mathrm{sec}$, have produced the same rise in skin temperature. The final computation was the value $\psi^{*}-$ the level of apparent warmth that corresponds to irradiance $\varphi^{*}$. In this way the psychophysical function for a 2-sec exposure was used as the standard to which other exposures were compared. The horizontal dashed line in Fig. 13 shows how the fraction $\psi / \psi^{*}$ would vary with duration of exposure if no adaptation occurred. In fact, the functions decrease; furthermore, the negative deceleration is rather typical of adapting systems (see, for example, Wallace, 1937). It may turn out, therefore, that the simplest concept of the sense organ consistent with the facts concerning apparent warmth is that of a highly adapting receptor system that is responsive simply to the temperature of some critical level or levels of the skin.

\section{REFERENCES}

CHRENKO, F. A. Threshold intensities of thermal radiation evoking sensations of warmth. J. Physiol, 1964, 173, 1-12.

EIJKMAN, E., \& VENDRIK, A. J. H. Dynamic behavior of the warmth sense organ. J. exp. Psychol., 1961, 62, 403-408.

EIJKMAN, E. G., \& VENDRIK, A. J. H. Psychophysical properties which can be related to electrophysiological data. In D. R. Kenshalo (Ed.), The skin senses. Springfield, Ill.: Charles C. Thomas, 1968. Pp. 160-175.

GAGGE, A. P., RAPP, G. M., \& HARDY, J. D. Mean radiant and operative temperature for high-temperature sources of radiant heat. Transactions of the American Society of Heating, Refrigerating, and Air-conditioning Engineers, 1964, 70, 419-423.

GAGGE, A. P., RAPP, G. M., \& HARDY, J. D. Effective radiant field and operative temperature necessary for comfort with radiant heating. Transactions of the American Society of Heating, Refrigerating, and Airconditioning Engineers, 1967, 73, Part I.

HARDY, J. D., \& OPPEL, T. W. Studies in temperature sensation. III. The sensitivity of the body to heat and the spatial summation of the end organ response. J. clin. Invest., 1937, 16, 533-540.

HARDY, J. D., WOLFF, H. G., \& GOODELL, H. Pain sensations and reactions. Baltimore: Williams and Wilkins, 1952.

HENDI ER, E., HARDY, J. D., \& MURGATROYD, D. Skin heating and temperature sensation produced by infrared and microwave irradiation. In C. M. Herzfeld (Ed.), Temperature: Its measurement and control in science and industry. Vol. 3, Part 3. New York: Reinhold, 1963. Pp. 211-230.

HERGET, C. M., GRANATH, L. P., \& HARDY, J. D. Thermal sensation and discrimination in relation to intensity of stimulus. Amer. J. Physiol., 1941, 134, 645-655.

KENSHALO, D. R., HOLMES, C. E., \& WOOD, P. B. Warm and cool thresholds as a function of rate of stimulus temperature change. Percept. \& Psychophys, 1968, 3, 81-84.

KENSHALO, D. R., \& SCOTT, H. A., Jr. Temporal course of thermal adaptation. Science, 1966, 151, 1095-1096.

LIPKIN, M., \& HARDY, J. D. Measurement of some thermal properties of human skin. $J$. appl. Physiol, 1954, 7, 212-217. 
MARKS, L. E. Brightness as a function of retinal locus. Percept. \& Psychophys, 1966, 1, 335-341.

STEVENS, J. C. Brightness function: Binocular versus monocular stimulation. Percept. \& Psychophys., 1967, 2, 451-454.

STEVENS, J. C., \& MARKS, L. E. Apparent warmth as a function of thermal irradiation. Percept. \& Psychophys., 1967, 2, 613-619.

STEVENS, S. S. Problems and methods of psychophysics. Psychol. Bull. $1958,55,177-196$

STEVENS, S. S. The psychophysics of sensory function. In W. A. Rosenblith (Ed.), Sensory communication. New York: John Wiley, 1961. Pp. 1-33.

STOLWIJK, J. A. J., \& HARDY, J. D. Skin and subcutaneous temperature changes during exposure to intense thermal radiation. J. appl Physiol. $1965,20,1006-1013$.
WALLACE, S. R. Studies in binocular interdependence. I. Binocular relations in macular adaptation. J. gen. Psychol, 1937, 17, 307-322.

\section{NOTES}

1. This research was supported partly by Contract F44620-67-C-0017 with the Air Force Office of Scientific Research and partly by Public Health Research Grant UI-00426 from the National Center for Urban and Industrial Health.

2. Address: John B. Pierce Foundation Laboratory, 290 Congress Ave, New Haven, Conn. 06519.

(Accepted for publication June 19, 1968.) 